- Details a two-year practice-based clinical evaluation of a packable resin composite material.

- A good recall rate was obtained.

- The material was found to be performing satisfactorily in general practice patients.

\title{
Two-year evaluation of restorations of a packable composite placed in UK general dental practices
}

\author{
F. J. T. Burke, ${ }_{1}^{1}$ R. J. Crisp, ${ }_{1}^{2}$ M. Balkenhol, ${ }^{3}$ T. J. Bell, J. J. Lamb, ${ }^{5}$ K. McDermott, ${ }^{6}$ C. Siddons ${ }^{7}$ and B. Weller ${ }^{8}$
}

\begin{abstract}
Objective The aim of this study was to assess the clinical performance at two years of 100 Solitaire 2 restorations placed in five United Kingdom dental practices by members of a practice-based research group. Method and materials Restorations were assessed after two years by a trained evaluator and the dental practitioner who had placed the material, for anatomic form, marginal adaptation, surface roughness, gingival condition and the presence or absence of secondary caries. In addition, the patients completed a questionnaire requesting details of the comfort and performance of the Solitaire 2 restoration(s).

Results A total of 88 (58 Class II and 30 Class I) restorations of Solitaire 2 placed in 49 patients (mean age 43 years) were assessed. Twelve restorations could not be evaluated because of patient unavailability for the dates of the examinations. Two Class II restorations (2\%) had failed by the time of the two-year evaluation and the remaining 86 restorations were found to be intact with no secondary caries. A high percentage of optimal scores were recorded for anatomic form and surface roughness. The colour match of two restorations (2\%) was recorded as an obvious mismatch, but otherwise no unacceptable scores were recorded.

Conclusions After two years of clinical service a high proportion (96\%) of the Solitaire 2 restorations that were available for re-examination, placed in general dental practice settings, were found to be performing satisfactorily.
\end{abstract}

\section{INTRODUCTION}

Packable composites

There is patient interest in tooth-coloured restorations in posterior teeth, both in the UK and the USA. ${ }^{1,2}$ Notwithstanding the appearance of their restorations, patients may also request toothcoloured restorations because of adverse publicity regarding mercury toxicity. Government agencies may also seek amalgam alternatives for environmental reasons. Results of surveys have

\footnotetext{
${ }^{1 *}$ Professor of Primary Dental Care; ${ }^{2}$ PREP Panel Coordinator, The University of Birmingham School of Dentistry: ${ }^{3}$ Research Dentist, Hereaus Kulzer, Hanau, Germany; 4,5,6,7,8UK General Dental Practitioners

${ }^{*}$ Correspondence to: F. J. T. Burke, The University of Birmingham School of Dentistry, St Chad's Queensway, Birmingham B4 6NN

Email:f.j.t.burke@bham.ac.uk
}

\section{Refereed paper}

Accepted 21 August 03

doi: $10.1038 /$ sj.bdj.4812654

๑ British Dental Journal 2005; 199: 293-296 shown that almost half of the Class I and one third of Class II restorations placed in the USA are now tooth-coloured ${ }^{3}$ and that one quarter of Class I restorations placed in the UK are made in resin-based composite (RBC) materials. ${ }^{4}$

Manufacturers have reacted to these factors by producing materials and devices which are intended to facilitate the placement of RBC materials in posterior teeth. Among these are sectional matrix systems and so-called packable composites, which are designed to handle more like amalgam than conventional composite materials. These materials are characterised by a high filler load and a filler distribution giving them a stiffer consistency than hybrid composites. ${ }^{5}$ It could be postulated that packable composites would deform a matrix band more readily than conventional resin composite systems, thereby producing a tighter contact with adjacent teeth, but Klein and co-workers have recently illustrated that there was no significant difference between a medium viscosity composite (Tetric Ceram: Vivadent, Schaan, Liechtenstein) and a high viscosity composite (Solitaire: Hereaus Kulzer, Wehrheim, Germany) in terms of proximal contact strengths (PCS), with both of these materials having a lower PCS than the amalgam material tested. ${ }^{6}$ Furthermore, there appears to be a risk of voids forming between increments of packable materials. ${ }^{7}$

The earliest of the packable resin composite materials, Solitaire (Hereaus Kulzer, Hanau, Germany), was introduced in 1997 and the material was subsequently developed, to become Solitaire 2 . This material was introduced in 1999. The material is a polyglas light-cured restorative material, comprising a novel, porous, matrix-integrating glass filler system and other fillers in conjunction with a highly cross-linked resin-based matrix. Solitaire 2 is indicated for Class I and II, restorations, primary dentition restorations and core-build-ups.

\section{Practice-based research}

The importance of practice-based research has been emphasised by Mandel, who considered that 'research is not only the silent partner in dental practice, it is the very scaffolding on which we build and sustain a practice. ${ }^{8}$ Since dental practice is where the majority of dental treatment is carried out in the UK, it would appear essential that the success or otherwise of a technique or material be evaluated in the dental practice situation. However, the majority of clinical evaluations in the past have been carried out on hospital-based patients. Among the problems related to this 
$\operatorname{are}^{9}$ that the patients may not be typical of those seen in dental practice, that the treatment may be carried out by well-qualified academics who are less likely to be subjected to the pressures of time and cost-effectiveness that prevail in dental practice, and, that the clinicians may have received pre-operative instructions in the handling and use of the materials under investigation. The principal strength of practice-based research is the variable nature of the work, with different practitioners from different undergraduate and postgraduate backgrounds contributing to the variations that are necessarily found in general dental practice. ${ }^{8}$

While involvement of practitioners in research projects in dental practice is one of the strengths of practice-based research, it has also been considered to be one of its weaknesses. ${ }^{9}$ Dental practices are established to treat patients effectively and efficiently. Time spent on research therefore cannot be used for patient treatment, and, as time has a cost, funding is required to reimburse the practitioners who are involved in research projects. Another difficulty is that practitioners are unlikely to have received extensive training in research methodology, although many recent UK graduates will have undertaken an 'elective' research project. There is therefore some value in practitioners forming research groups, whereby experience may be pooled, academic advice obtained and funding for projects achieved. By this means, some of the difficulties in carrying out research in dental practice can be overcome. One such group is the PREP (Product Research and Evaluation by Practitioners) Panel.

\section{The PREP Panel}

In 1993 it was considered appropriate to establish a group of UKbased practising dental practitioners who were prepared to complete evaluations of new materials and techniques in the practice environment. As a result, the PREP Panel ${ }^{10}$ was established. To date, a total of 40 evaluations, including 'handling' evaluations and clinical trials, have been completed. The PREP panel presently has 24 members with an average time since graduation of 21 years. Four of the panel members are female.

It is the aim of this paper to report the clinical performance, at two years, of 100 Solitaire 2 restorations placed in the practices of five PREP Panel members.

\section{MATERIAL AND METHODS}

\section{Selection of dentists}

Five general dental practitioners were chosen at random from the members of the PREP Panel. The practices selected were located in Douglas (Isle of Man), York, Liverpool, Ilkley (Yorkshire) and Holt (Norfolk). Each practitioner was requested to place 20 Solitaire 2 restorations for the evaluation. The initial assessment of the restorations, at placement, was recorded by the PREP Panel member who had placed the restorations. The two-year reviews were carried out by a trained and calibrated evaluator, along with the PREP Panel member who had placed the restorations. Ethics Committee approval was obtained prior to commencement of the evaluation. Informed written consent was obtained from all patients prior to registration for participation in the evaluation.

\section{Number and selection of patients}

A maximum of four restorations were placed in any one patient. To be included in this study a patient had to be between 18 and 65 years of age, have molar supported permanent dentitions free of any clinically significant occlusal interferences, have well maintained dentitions free of any untreated periodontal disease, have one to four Class I or II cavities requiring restoration, and, be a regular dental attender who agreed to return for the assessments.

Patients were excluded from participating in the evaluation if they reported a history of any adverse reaction to clinical material of the types used in the evaluation, if there was evidence of occlusal parafunction and/or pathological tooth wear, or if they were pregnant or had medical and/or dental histories which could have possibly complicated the provision of the proposed restoration.

\section{Selection of teeth}

For a tooth to be included in the evaluation it must be of typical size and morphology, have sufficient enamel and dentine to justify the placement of a restoration of the type evaluated, be free of cracks and signs of abnormal wear.

\section{Pre-operative procedure}

Each patient completed and signed a consent form. The pre-operative status of the gingival tissues adjacent to the tooth/teeth to be restored was assessed using the codes and criteria set out in Table 1. Appropriate vitality and radiographic assessments were completed where indicated clinically.

\section{Operative procedure}

Where indicated clinically and with the approval of the patient, appropriate local anaesthesia was given. The tooth/teeth were prepared using conventional instruments and techniques. The preparations had cavosurface margins of approximately $90^{\circ}$, gingival margins apical to any remaining approximal contact areas, and rounded internal line and point angles. Resistance and retention form was achieved as well as possible in relation to the remaining tooth tissues.

The tooth/teeth were restored as follows:

They were isolated using cotton rolls, with the use of rubber dam being limited to those cases in which isolation was only assured under rubber dam. Where indicated clinically, a calcium hydroxide material was used to cover very deep areas of the preparation in dentine. This sub-base was then covered with a $1 \mathrm{~mm}$ layer of resin-modified (light-cured) glass ionomer cement.

Two bonding systems were used. For patient numbers 1, 3, 5, etc, restorations were placed using the Gluma Solid Bond system (Hereaus Kulzer, Hanau, Germany), while for patient numbers 2, 4, 6 , etc, restorations were placed using the Gluma One Bond system (Hereaus Kulzer, Hanau, Germany).

The restorations were placed with adherence to the manufacturer's recommendations for the handling and placement of restorations of Solitaire 2 and Gluma Solid Bond or Gluma One Bond.

The restorations were placed in increments, the first being $1 \mathrm{~mm}$ deep, and the remaining increments being $2 \mathrm{~mm}$. Matrices and other devices to facilitate the placement of the restoration were selected and used at the discretion of the clinician placing the restorations.

\section{Two-year assessment}

Registration and baseline assessment forms were completed after placement of the restorations. The two-year review of the restorations was undertaken by one trained and calibrated examiner in conjunction with the PREP Panel member who placed the restorations. The procedure for each review was as follows.

All restorations were inspected and assessed for the purposes of completing an assessment form based upon the criteria laid down by Ryge. ${ }^{11}$ The assessment included evaluation of:

- anatomic form

- marginal adaptation

- surface roughness

- sensitivity/discomfort

- condition of adjacent gingivae

- presence or absence of secondary caries.

The codes and ratings used, together with the relevant criteria are set out in Table 1 . When decisions of the assessors differed, a 
consensus opinion was agreed before the patient was dismissed. In addition to the above, the two-year review included photographic records of a representative proportion of the restorations. In the event of the restoration being found to be unsatisfactory, details of the mode of failure were recorded and the necessary remedial work carried out. Patients attending for review were recompensed for their expenses and a fee was paid to the PREP panel member for the surgery time taken for the evaluations. Each patient paid the normal fee for the restoration to the PREP Panel member.

Before each patient was dismissed, they were asked to complete a questionnaire requesting details of the comfort and performance of the Solitaire 2 restoration(s).

\section{RESULTS}

A total of 49 patients (mean age 43 years) who had received a total of 88 restorations, presented for examination at the two-year review appointments. One Class II restoration (a large mesioocclusal-distal restoration) had been replaced at 10 months after a fracture was detected across the distal box. The remaining 87 restorations were included in the two-year evaluation. One further Class II (a large pin-retained mesio-occlusal-distal restoration) had failed by the time of the two-year evaluation (Fig. 1). The distribution of the remaining 86 restorations, according to tooth type and Class of restoration, is presented in Table 2. No secondary caries was associated with any of the restorations.

\section{Anatomic form}

The optimal score was obtained in 84 (98\%) of the restorations assessed, with no unacceptable scores recorded.

\section{Marginal adaptation}

The proximal and occlusal margins were reviewed separately with no unacceptable scores recorded. Optimal scores were recorded on $88 \%$ of the proximal margins and 90\% of the occlusal margins.

\section{Marginal discolouration (a) enamel}

No unacceptable scores were recorded, either on the occlusal or proximal margins. Eighty-five per cent of the restorations achieved an optimal rating for occlusal marginal discolouration. The remaining 15\% showed slight discolouration of the occlusal margins, which could be polished away. Eighty-six per cent of the proximal margins were assessed as optimal for marginal discolouration, 9\% showed slight discolouration which could be polished away and 5\% showed obvious stain.

\section{Marginal discolouration (b) dentine}

No restorations had a gingival margin in dentine which could be assessed for marginal discolouration.

\section{Surface roughness}

No unacceptable scores were recorded and 93\% of the restorations were assessed as optimal for occlusal and proximal surface roughness.

\section{Colour match}

Eighty-four per cent of the restorations achieved optimal scores, with 14\% exhibiting a slight mismatch. Two restorations (2\%) showed an obvious colour mismatch.

\section{Gingival scores}

The gingival score was not related to the presence or absence of an adjacent Solitaire 2 restoration and as a consequence there was no evidence of any adverse soft tissue effect attributable to the presence of such a restoration.

The results are summarised in Table 3.

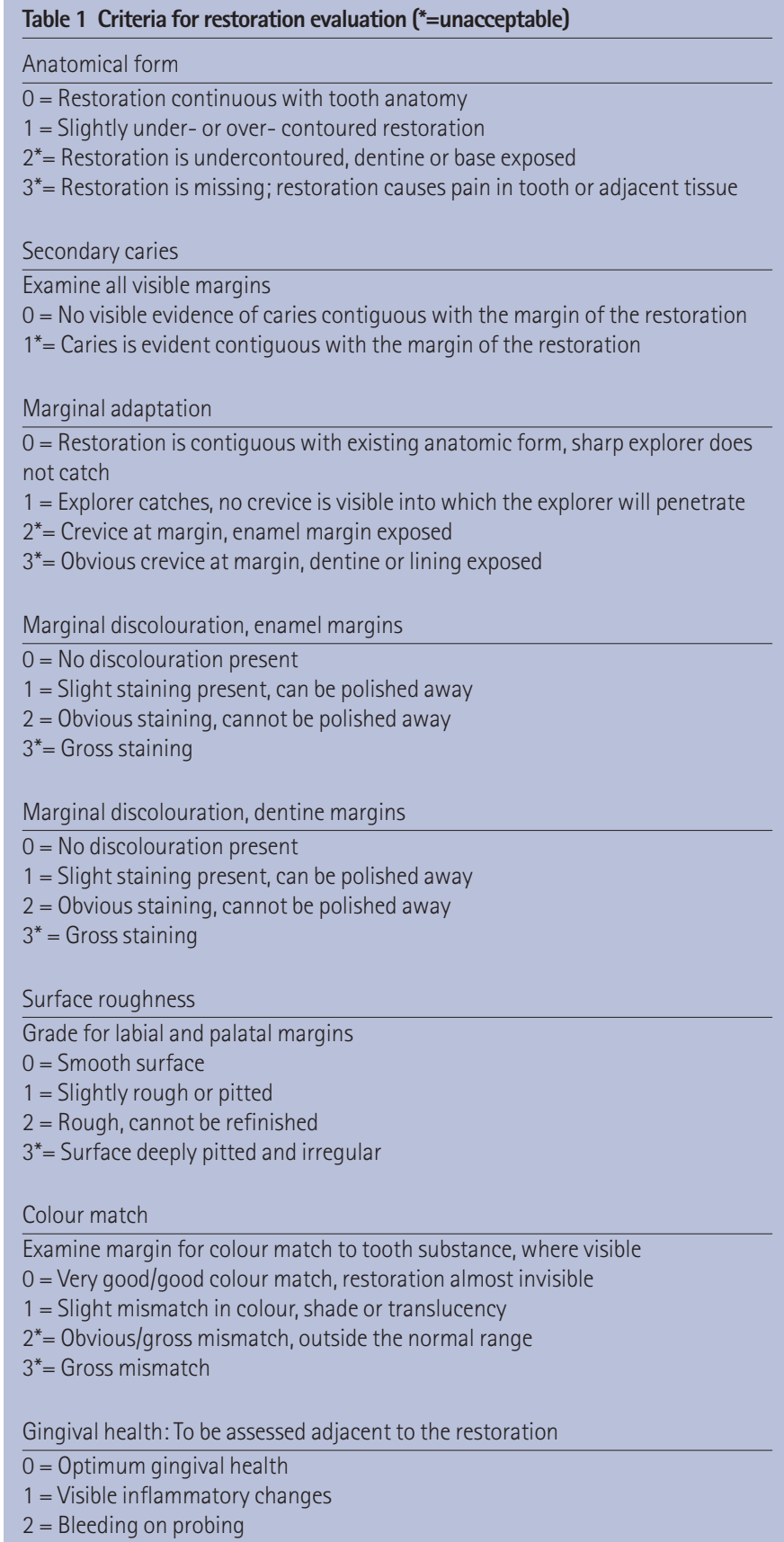

Table 2 Distribution of the Solitaire 2 restorations assessed at two years (By tooth type and class of restoration)

\begin{tabular}{lccccc}
\hline & \multicolumn{2}{c}{ Maxillary } & \multicolumn{2}{c}{ Mandibular } \\
\hline & Total & Molar & Premolar & Molar & Premolar \\
\hline Class I & 30 & 11 & 0 & 17 & 2 \\
Class II & 56 & 11 & 18 & 16 & 11 \\
Total & 86 & 22 & 18 & 33 & 13
\end{tabular}

\begin{tabular}{|c|c|c|c|c|c|}
\hline \multirow[b]{3}{*}{ Criteria } & & \multicolumn{4}{|c|}{ Rating (\%) } \\
\hline & & \multicolumn{3}{|c|}{ Acceptable } & \multirow{2}{*}{\begin{tabular}{|c} 
Unacceptable* \\
3
\end{tabular}} \\
\hline & & 0 (Optimal) & 1 & 2 & \\
\hline Anatomic form & & 98 & 2 & 0 & 0 \\
\hline Marginal & Proximal & 88 & 12 & 0 & 0 \\
\hline adaptation & Occlusal & 90 & 10 & 0 & 0 \\
\hline Marginal & Proximal & 86 & 9 & 5 & 0 \\
\hline discolouration & Occlusal & 85 & 15 & 0 & 0 \\
\hline Surface & Proximal & 93 & 7 & 0 & 0 \\
\hline roughness & Occlusal & 93 & 7 & 0 & 0 \\
\hline Colour match & & 84 & 14 & $2^{*}$ & 2 \\
\hline
\end{tabular}


Fig. 1

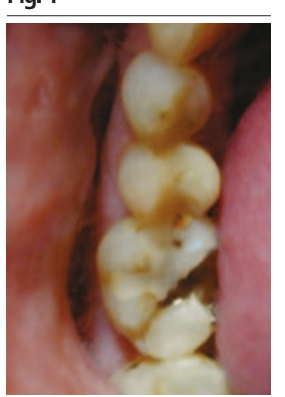

Fig. 2

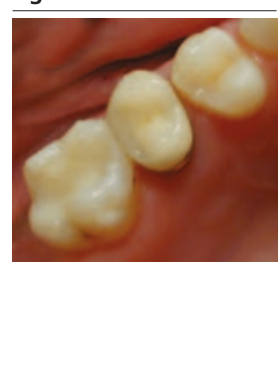

Fig. 1 Failed pin-retained mesio-occlusal-distal restoration in lower molar tooth

Fig. 2 Occlusal restoration in Solitaire 2 in lower first molar tooth

Fig. 3 Class II restoration in Solitaire 2 in lower second premolar tooth

\section{Patient questionnaire}

All $49(100 \%)$ of the patients were satisfied with the restorations both in appearance and comfort. Three patients (6\%) reported slight initial sensitivity, which settled within 14 days. One patient complained of sensitivity, which did not resolve, and the tooth (an upper premolar) was root treated.

\section{DISCUSSION}

The clinical performance of 88 Class I and II restorations of Solitaire 2 placed in general dental practice over a mean period of 24 months has been investigated. The recall rate, of 88 restorations from 100 placed, could be considered good, given the logistical difficulties in having the examiner travel to the five practices involved in the study at times when patients were able to attend for examination, and is within the range obtained in clinical evaluations carried out in dental schools. No details are available for the restorations/patients who were unable to present for assessment, but it is understood, from conversations with the dental practitioners involved in the study, that the non-attending patients were unavailable for the limited date and time that the calibrated examiner visited their practices. The practitioners who placed the restorations were not aware of any problems with the restorations placed in the group of non-attenders. Indeed, it could be postulated that the patients, having been selected as being regular attenders, would have returned to their dentists had any difficulties been experienced with their restorations. No differences were apparent in the restorations placed in the attenders and non-attenders, except that the missing restorations were more likely to be in the Gluma One group.

At two years a high percentage of optimal scores were recorded for both anatomic form (98\%) and surface roughness (93\% both occlusal and proximal). It should also be noted that $86 \%$ of the restorations were assessed as being in normal or heavy occlusion. Marginal adaptation scores were also 88\% optimal or above. All the patients continued to find the restorations satisfactory.

As at the one-year evaluation, ${ }^{12}$ marginal discolouration scores were carefully assessed, as most of the restorations were replacing old amalgam restorations with some degree of local discoloured, but sound, enamel. The number of optimal scores for marginal discolouration showed a slight decrease from the one-year evaluation but no unacceptable scores were recorded. Also as at one-year, ${ }^{12}$ the lowest number of optimal scores (84\%) was for colour match, with two (2\%) restorations with an obvious colour mismatch assessed. However a slight degree of mismatch in tooth coloured restorations in posterior teeth has been argued as desirable ${ }^{13}$ and all of the patients, when questioned, were still satisfied with the appearance of the Solitaire 2 restorations.

These results indicate good clinical performance of the composite tested, when placed under general dental practice conditions, with $96 \%$ of the restorations at two-years performing satisfactorily (Figs 2 and 3). While two-year assessment cannot be considered to provide an indication as to the long term performance of the material under test, shorter term evaluations are of value in showing early and/or catastrophic failures if a material is performing suboptimally. The results are in keeping with a number of studies which indicate satisfactory performance of RBCs, such as the 10year evaluation, by Mair, ${ }^{14}$ of restorations placed in a hospital environment and the meta-analysis carried out by El Mowafy and co-workers. ${ }^{15}$ Additionally, the American Dental Association, having reviewed the literature, recommend $\mathrm{RBC}$ as being suitable for medium-size class I and II restorations. ${ }^{16}$

There are few reports of the performance of recently-introduced packable RBCs, although Perry and co-workers have reported the satisfactory performance of the packable composite Surefil (Dentsply, Weybridge UK). ${ }^{17}$ A recently-published study of a reduced shrinkage composite (Z250:3M ESPE, St.Paul, MN, USA) used as an alternative to dental amalgam in a general dental practice setting has indicated clinically acceptable performance at one year. ${ }^{18}$ The failure rate in the present study, of two restorations from the 88 assessed, could be considered satisfactory. At one-year, one restoration had failed and at the two-year review one further very large pin-retained restoration (Fig.1) had failed, with the restoration fracturing through a pin. This restoration had been placed as an interim restoration, as a crown had been indicated, but the patient had been unable to afford such treatment at the time of treatment. This is an example of the type of situation which may prevail in dental practice, as opposed to evaluations carried out in a dental school where financial pressures are likely to be less acute.

\section{CONCLUSION}

After two years of clinical service, a high proportion (96\%) of the Solitaire 2 restorations that were available for re-examination, placed in general dental practice settings in conjunction with the Gluma Solid Bond and Gluma One Bond bonding systems, were found to be performing satisfactorily.

The authors acknowledge the support of Hereaus Kulzer for this project, and thank the patients for their co-operation.

1. Reinhardt J W, Capilouto M L. Composite resin esthetic dentistry survey in New England. J Am Dent Assoc1990; 120: 541-544.

2. Burke FJ T. Patient acceptance of posterior composite restorations. Dent Update1989; 16: $114-120$.

3. Brown LJ, Wall T, Wassenaar J D. Trends in resin and amalgam usage as recorded on insurance claims submitted by dentists from the early 1990s and 1998. J Dent Res 2000; 79: 461; Abstract 2542.

4. Burke FJ T, Wilson N H F, Cheung S-W, Mjor I A. Influence of patient factors on age of restorations at failure and reasons for their placement and replacement. J Dent 2001; 29: $317-324$

5. Manhart J, Kunzelmann K-H, Chen HY, Hickel R. Mechanical properties and wear behavior of light-cured packable composite resins. Dent Mater 2000; 16: 33-40.

6. Klein F, Keller A K, Staehle H J, Dorfer C E. Proximal contct formation with different restorative materials and techniques. Am J Dent 2002; 15: 232-235.

7. Opdam N J M, Roeters FJ M, Joosten M, vd Veeke 0 . Class I composite restorations placed with a packing or injection technique. Dent Res 2000; 79: 149; Abstract 42.

8. Mandel I D. Clinical research - the silent partner in dental practice. Quintessence Int1993; 24: 453-463.

9. Burke F J T, Crisp R J, McCord J F. Research in dental practice: A SWOT analysis. Dent Update 2002; 29: 80-87.

10. Burke F J T, Wilson N H F. Introducing the PREP panel. Dent Pract 1994; 32: 30.

11. Ryge G. Clinical criteria. Int DentJ 1980; 30: 347-357

12. Crisp R J, Burke FJ T, Balkenhol M. Solitaire II restorations placed in general practice: one-year preliminary evaluation. J Dent Res 2001; 80: 201: Abstract 1323.

13. Burke F J T Shortall A C C. Successful restorations of load-bearing cavities in posterior teeth with direct-placement resin-based composite. Dent Update 2001: 28: 388-398.

14. Mair L H. Ten-year clinical assessment of three posterior resin composites and two amalgams. Quint Int.1998: 29: 483-490.

15. El-Mowafy $O M$, Lewis D W, Benmergui $C$, Levinton C. Meta-analysis on long-term clinical performance of posterior composite restorations. J Dent1994: 22: 33-43.

16. ADA Council on Scientific Affairs: ADA Council on Dental Benefit programs. Statement on posterior resin-based composites. J Am Dent Assoc 1998; 129: 1627-1628.

17. Perry R, Kugel G, Leinfelder K. One-year clinical evaluation of Surefil packable composite. Contin Compend Dental Educ 1999; 20: 544-553.

18. Wilson M A, Cowan A J, Randall R C, Crisp R J, Wilson N H F. A pratice-based randomized controlled clinical trial of a new resin composite restorative : one-year results. Oper Dent. 2002: 27: 423-429. 